https://www.journal-imab-bg.org
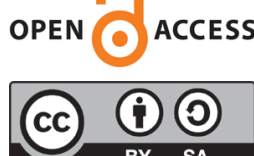

\section{RESILIENT LINING MATERIALS FOR REMOVABLE DENTURES: COMPOSITION AND TECHNOLOGY TYPES,}

Mariana Yankova, Bozhidar Yordanov, Mariana Dimova-Gabrovska, Nikolay Apostolov

Department of Prosthetic Dental Medicine, Faculty of Dental Medicine, Medical University - Sofia, Bulgaria.

\section{SUMMARY}

For patients with removable dentures, requiring uniform distribution of masticatory forces, the use of elastic relining materials is indicated. They are classified with respect to various characteristics: chemical composition, technology, polymerisation process, final hardness - Shore A, etc.

Two basic relining methods have been described in the scientific literature - direct (clinical), and indirect (laboratory). The combination of a laboratory method and a clinical procedure is named direct-indirect method. Direct and direct-indirect techniques are used for cold curing relining materials, while indirect techniques are used for heat curing elastic relining materials.

The good knowledge of the types, techniques, processing and basic characteristics of elastic relining materials is an important factor for predictable results in the prosthetic treatment with removable dentures.

Keyword: elastic relining materials, relining methods, direct (clinical), and indirect (laboratory) methods, direct-indirect method

\section{INTRODUCTION}

Excessive bone resorption, thin and non-pliable mucosa, exostosis or painful neurogenic points in edentulous patients require more specific methods of treatment with complete dentures $[1,2]$, which provide a more even distribution of masticatory pressure [3] and reduce mucosal trauma. Such clinical cases can be resolved by using resilient lining materials for complete dentures.

\section{Classification and composition of resilient lining} materials (RLMs)

Resilient lining materials can be classified according to different characteristics: chemical composition, technology, type of polymerization, final hardness (by Shore A), etc. Based on their chemical composition, resilient resins were classified into acrylic, silicone and vinyl by Todorov [4] in 1989. Today, Anastasov [5] confirms this classification. Some authors $[6,7,8]$ add two new groups and divide resilient resins on the basis of their chemical composition into: 1. Acrylic; 2. Silicone; 3. Vinyl; 4. Polyurethane and 5. Polyphosphazene.

Hayakawa [9] also adds two new groups and divides
RLMs into four groups:

1. Acrylic denture liners (DLs) - Coe-soft (GC America Inc., USA) for direct technique and Super-soft (GC America Inc., USA) for indirect technique;

2. Silicone DLs - Mollosil (Detax, GmbH \& Co, KG, Germany) for direct technique and Molloplast B (Detax, $\mathrm{GmbH} \& \mathrm{Co}, \mathrm{KG}$, Germany) for indirect technique;

3. Fluorinated DLs (containing fluorinated copolymers) - Kurepeet Dough (Kreha Chemical, Tokyo, Japan) only for indirect technique;

4. Olefin DLs - Molteno (Molten, Japan) only for indirect technique.

In another publication, Hayakawa et al. [10] have reported a new light-curing material based on polyisoprene Clearfit LC (CL; Kuraray, Japan).

A large group of authors [7, 11-18] classify resilient resins in five groups, based not only on their chemical composition, but also on the type of polymerization and indications for use:

1. Heat-curing acrylic resilient resins - Eversoft (Dentsply Int., USA), Super-soft (GC America Inc., USA), VertexSoft (Vertex-Dental B.V., Netherlands);

2. Self-curing acrylic resilient resins - Permasoft (Dentsply Int., USA), Durabase (Dental Mfg Co., USA), Coe Soft (GC America Inc., USA);

3. Heat-curing silicones - Molloplast B (Detax, $\mathrm{GmbH}$ \& Co., Germany), Luci-Soft (Dentsply Int., USA), Permaflex (Kohler, Germany), etc.;

4. Self-curing silicones - UfiGel P (VOCO GmbH, Germany), UfiGel SC (VOCO GmbH, Germany), Mucopren soft (Kettenbach GmbH \& Co., Germany), Dentusil (Bosworth, Reline Soft (GC America Inc., USA), GC Reline Ultrasoft (GC America Inc., USA), Softreliner Tough (Tokuyama, Japan), Mucosoft (Parkell Inc., USA);

5. Tissue conditioners (healing liners) - Viscogel (Dentsply Int., USA), Coe Comfort (GC America Inc., USA), etc.

For clarity, Tables 1, 2 and 3 give the basic chemical components of some of the listed materials.

Acrylic hard resins [table. 1] become resilient if plasticizers - from $30 \%$ to $60 \%$ - are added. Originally, powdered plasticizers, darkeners $\left(\mathrm{TiO}_{2}\right)$, coloring agents $\left(\mathrm{Fe}_{2} \mathrm{O}_{3}\right)$, as well as the liquid plasticizer dioctyl phthalate were used. 
Table 1. Acrylic-based resilient lining materials

\begin{tabular}{|l|l|l|}
\hline Material Composition & \multicolumn{1}{c|}{ Polymer } & \multicolumn{1}{c|}{ Monomer } \\
\hline$\underline{\text { Vertex Soft heat-curing }}$ & Poly(ethyl methacrylate) & Acetyl tributyl citrate + MMA \\
\hline$\underline{\text { Eversoft heat-curing }}$ & Poly(ethyl methacrylate) & $\begin{array}{l}\text { Dibutyl phthalate + ethyl acetate+ethyl } \\
\text { alcohol+methyl ethyl ketone }\end{array}$ \\
\hline$\underline{\text { Astron Soft light-curing }}$ & Poly(ethyl methacrylate) & Bis-EMA, butyl methacrylate \\
\hline
\end{tabular}

Representatives of this group are: Orthoplast (Russia), Palasiv 62 (Germany), the heat-curing Coe Super soft (GC America Inc., USA) and others. [4]

Today, the most common plasticizers are dibutyl phthalate or dibutyl glycolate [5]. The bond with the solid PMMA base is chemical. Some resilient resins contain the hydrophilic acrylic monomer hydroxyethyl methacrylate
(HEMA) [5].

Healing liners, also called tissue conditioners, are acrylic-based resilient materials (PEMA) that remain soft for a limited time (days to weeks). Their chemical composition is shown in Table 2. The molecular weight of the plasticizer contained therein and the percentage of alcohol content determine their properties.

Table 2. Healing liners (Tissue conditioners)

\begin{tabular}{|c|c|c|c|}
\hline Material Composition & Polymer & Solvent & Plasticizer \\
\hline Viscogel & $\begin{array}{l}\text { Poly(ethyl methacrylate) - } 86.2 \% \\
\text { Poly(methyl methacrylate) }-13.8 \%\end{array}$ & $\begin{array}{c}\text { ethyl alcohol } \\
4.9 \%\end{array}$ & $\begin{array}{l}\text { Dybutyl phthalate }-8.2 \% \\
\text { butyl phthalyl butyl glycolate }-86.9 \%\end{array}$ \\
\hline Coe Comfort & Poly(methyl methacrylate) - $100 \%$ & ethyl alcohol & $\begin{array}{l}\text { Dybutyl phthalate } \\
\text { Benzyl benzoate }\end{array}$ \\
\hline Coe Soft & Poly(ethyl methacrylate - $100 \%$ & $\begin{array}{c}\text { ethyl alcohol } \\
15.2 \%\end{array}$ & $\begin{array}{l}\text { Di-n-butyl phthalate }-49.7 \% \\
\text { benzyl salicylate }-35.1 \%\end{array}$ \\
\hline GS Soft Liner & Poly(ethyl methacrylate - $100 \%$ & $\begin{array}{c}\text { ethyl alcohol } \\
14.8 \%\end{array}$ & $\begin{array}{l}\text { Butyl phthalyl butyl glycolate }-8.9 \% \\
\text { Dybutyl phthalate }-4.3 \%\end{array}$ \\
\hline
\end{tabular}

For example, Visco-gel (Dentsply Int., USA) contains a low percentage of ethyl alcohol - 4.5\%-4.9\% [19, 20] and a high molecular weight plasticizer [mol. weight 336] as opposed to Coe Comfort (GC America Inc., USA), which contains a low molecular weight ester of benzyl benzoate [mol. weight 212]. SR - Ivoseal (Ivoclar Vivadent, Liechtenstein) is the tissue conditioner with the highest content of ethyl alcohol - 48.1\% [21].
Silicone resilient resins [Table 3] have a composition similar to silicone impression materials. By polycondensation or polymerization, the linear polymer chain of the principal component - polydimethyl siloxane - is extended and cross-linked and the material acquires elastic consistency. The bond with the denture base is mechanical [5]. They can be divided into heat-curing and cold-curing, as well as temporary and long-term resilient materials.

Table 3. Silicone-based resilient lining materials

\begin{tabular}{|l|l|l|l|l|}
\hline \multicolumn{1}{|c|}{ Composition } & \multicolumn{1}{|c|}{ Polymer } & Cross-linking agent & \multicolumn{1}{c|}{ Catalyst } & Adhesive \\
\hline Molloplast B & $\begin{array}{l}\text { Poly (dimethyl } \\
\text { siloxane) }\end{array}$ & Acryloxy alkyl silane & $\begin{array}{l}\text { Heat + benzoil } \\
\text { peroxide }\end{array}$ & $\begin{array}{l}\text { y-methacryloxy propyl } \\
\text { trimethoxysilane }\end{array}$ \\
\hline Flexibase & $\begin{array}{l}\text { Poly (dimethyl } \\
\text { siloxane) }\end{array}$ & Tri ethoxy silanol & Dybuthyltin dilaurate & $\begin{array}{l}\text { Silicone polymer in } \\
\text { a solvent }\end{array}$ \\
\hline
\end{tabular}

Polysiloxanes are on the basis of silicone resilient resins. The known in the past in Bulgaria resilient resin Ortosil (Russia) is a polydimethyl siloxane rubber with a cross-linking agent - methyl triacetoxy silane - added in the liquid.
The resin Lucopren (Czech Republic) contains 90\% dihydroxy-polydimethylsiloxane, $5 \% \mathrm{SiO}_{2}$ and others. [4]. Even today, silicon dioxide $\left(\mathrm{SiO}_{2}\right)$ is added to some coldcuring silicone materials for higher density. Megabase Soft 
(Dreve Dentamid GmbH, Germany) is a two-component material containing silicon dioxide $\left(\mathrm{SiO}_{2}\right)$ and polydimethyl-polymethyl-hydrogen siloxane and vinylmethyl-polymethyl siloxane [7].

One of the most popular lining materials, known for more than 20 years, is Molloplast B (Detax, GmbH \& Co., Germany). It is a heat-curing single component of silicone resin. The polymerization is activated by heat (boiling water for 2 hours), and the bond with the denture base is accomplished by an adhesive, which is a silicone polymer in a solvent. Heat-curing silicones consist of polydimethylsiloxane and benzoyl peroxide. Cross-linking is initiated by free radicals generated by the decomposition of organic peroxides at high temperatures.

Flexibase (Flexico Developments Ltd., London, UK) is available as powder and liquid. The liquid comprises a catalyst, a mixture of dibutyltin dilaurate and ethyl polysilicate. Here again, the bond with the denture base is accomplished with an adhesive that is a silicone polymer in a solvent.

Vinyl resilient resins can be polyvinyl chloride or polyvinyl acetate polymers with added plasticizers, crosslinking agents and color stabilizers. They are mechanically bound to PMMA. Plasticizers for polyvinyl chloride polymers are dibutyl acrylate and dioctyl phthalate.

Famous brands from this group are Elladent 100 (Russia) for lining and Elastoplast (Russia) for boxing bracelets.

Today, on the market of dental products, there are silicone-based RLMs that have the same chemical composition as the polymerization (addition) silicones known as A-silicones. The main chemical element is polydimethylsiloxane with terminal vinyl groups $(-\mathrm{CH}=$ $\mathrm{CH}_{2}$ ) or vinyl-polydimethylsiloxane. They are two-component pastes containing polyvinyl siloxanes and a platinum catalyst.

The main representatives are Mucopren soft (Kettenbach GmbH \& Co. KG, Germany), Sofreliner tough medium (Tokuyama, Japan), Sofreliner medium soft (Tokuyama, Japan), Sofreliner super soft (Tokuyama, Japan), GC reline soft (GC America Inc., USA), GC reline extra soft (GC America Inc., USA), GC reline ultra soft (GC AmericaInc., USA) [22]. The Mucopren soft adhesive (Kettenbach $\mathrm{GmbH} \&$ amp; Co. KG, Germany) contains methacrylate, ethyl acetate and others, and the coating sealer - vinyl polysiloxane and a platinum catalyst. Elite Soft relining (Zhermack, Italy), Elite Super Soft relining (Zhermack, Italy), and Silagum Comfort (DMG, Germany) also belong to this group. Silagum Comfort primer contains ethyl acetate modified by the addition of polyacrylate. The Silagum Comfort (DMG, Germany) coating sealer contains vinyl silicone, hydrogen silicone and platinum catalyst [23].

Some authors [24, 25, 26] suggest a simplified classification of RLMs, based on their chemical composition, the first group comprising acrylic-based lining materials and the second - silicone-based lining materials, and depending on the time of stay in the mouth - temporary and long-term RLMs.
Abe [27] notes that resilient resins can be acrylic-, silicone- and polyolefin-based. He describes the material Mucopren soft (Kettenbach GmbH \& Co. KG, Germany), which falls into the new subgroup of silicone resilient resins (the group of vinyl polysiloxanes - A silicones).

In 2014, a group of authors from Poland [7] made an extremely thorough analysis of RLMs. They describe in detail the chemical composition of resilient resins. The analyzed resilient acrylic-based materials are available as two-component powder and liquid systems. The powder is polyethyl methacrylate (PEMA) with an organic peroxide initiator. The liquid contains a high molecular weight monomer, such as: ethyl methacrylate, n-propyl methacrylate, n-butyl methacrylate.

Plasticizers are aromatic esters, such as dibutyl phthalate and ethyl acetate. The composition of these materials includes also cross-linking agents of ethylene glycol dimethacrylate type.

According to the technology, RLMs are divided into:

1. Heat-curing RLMs for indirect technique - LUCI SOF (Dentsply Int., USA) - $100^{\circ} \mathrm{C} / 2.5 \mathrm{~h}$, Molloplast $B$ (Detax, GmbH \& Co., KG, Germany) - $100^{\circ} \mathrm{C} / 2$ h [24].

2. Cold-curing RLMs for direct and direct-indirect technique - Mollosil (Detax, GmbH \& Co, KG, Germany) [28].

3. Light-curing RLMs - Perform Soft (Coltene Whaledent Inc., USA), Light Liner Soft (Bosworth, USA), Resiline (Dentsply Int., USA), Astron LC (Astron Dent Cor.) [23, 29, 30].

In the direct technique, polymerization takes place for about 5 minutes in the oral cavity of the patient and in the indirect technique, this can be done on the working cast for about 30 minutes at room temperature $\left(23^{\circ} \mathrm{C}\right)$ or for about 10 minutes in a polymerization apparatus at a temperature of $40^{\circ} \mathrm{C}-45^{\circ} \mathrm{C}$ : Elite Soft relining (Zhermack, Italy), Mollosil (Detax, GmbH \& Co., KG, Germany), etc. For light-curing RLMs, polymerization takes place for 215 minutes for the different materials.

\section{Lining techniques}

The scientific literature describes two main types of lining techniques - direct (clinical) and indirect (laboratory). When the laboratory technique is associated with an immediate clinical procedure, it is called direct-indirect [31]. Direct and direct-indirect techniques are applied to coldcuring RLMs, while indirect techniques - to heat-curing RLMs.

\section{Direct technique}

Direct technique is a completely clinical procedure comprising a complex of intraoral and extraoral steps. A basic requirement is to use cold-curing RLMs, the most popular of which are silicone-based. In the direct technique, a new base of resilient material is added to a denture of hard acrylic resin, pre-fabricated according to conventional technology. In order to achieve successful relining, it is necessary to treat the existing denture in a way to provide enough space for the new material and a good bond 
with the hard acrylic base.

Providing the necessary distance can be done in two main ways: 1) by using a spacer or 2) by abrading (a step, described in almost all instructions of resilient material manufacturers).

\section{By using a spacer}

Abe [27] describes a technique, in which $10 \mathrm{~mm}$ long, $5 \mathrm{~mm}$ wide and $2 \mathrm{~mm}$ thick hard resin stoppers are placed in the frontal and the two molar areas after adjustment of the fabricated denture. Relining is done in two stages. First, the resilient material is uniformly applied to the mucosal surface of the denture and then, the denture is inserted into the patient's mouth and pressed against the prosthetic field. The stoppers limit the excessive sinking and provide the required uniform thickness $(2 \mathrm{~mm})$ of the resilient material. After 2-3 minutes, the denture is removed from the patient's mouth and the stoppers are removed. Additional material is placed on their sites and the denture is returned to the mouth for final polymerization.
Another way to provide the necessary space for the new material by using a spacer is described by Tata and Nandeeshwar [32]. The method is applied, when relining is pre-planned as the last stage of denture fabrication. In this method, the denture is fabricated on a duplicate working cast in the following manner: A $2 \mathrm{~mm}$ thick wax plate is adapted to the first working cast. Window frames are cut along the alveolar ridge in the area of canines and molars. The cast is duplicated by using an alginate impression material. The denture, fabricated on the duplicated cast will have resin feet (stoppers) corresponding to the window frames, thus providing the required space for the resilient material. It is not clear from the publication whether the stoppers are later replaced with a resilient material or not.

\section{By abrading}

Providing sufficient space for the resilient material by abrading is performed with a metal milling cutter, after preliminary marking of the required depth of the relining layer with a round bur [Figure 1].

Fig. 1. a) Marking the depth with a round bur b) Removing a layer of resin by abrading.

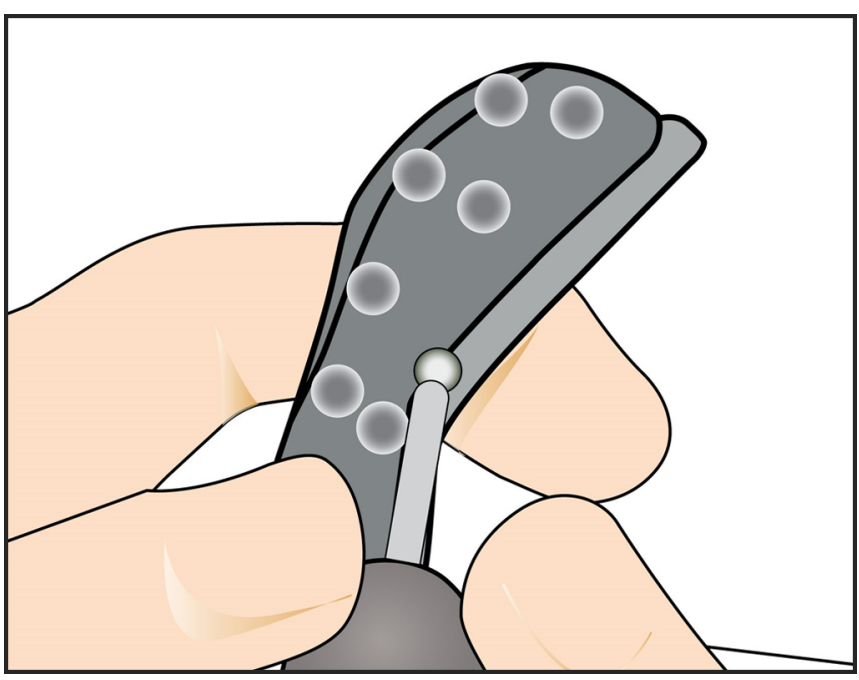

An important step in the methodology is the treatment of the prosthetic edge in the area of the valve zone. It is shortened by $2-3 \mathrm{~mm}$ and thinned, with formation of

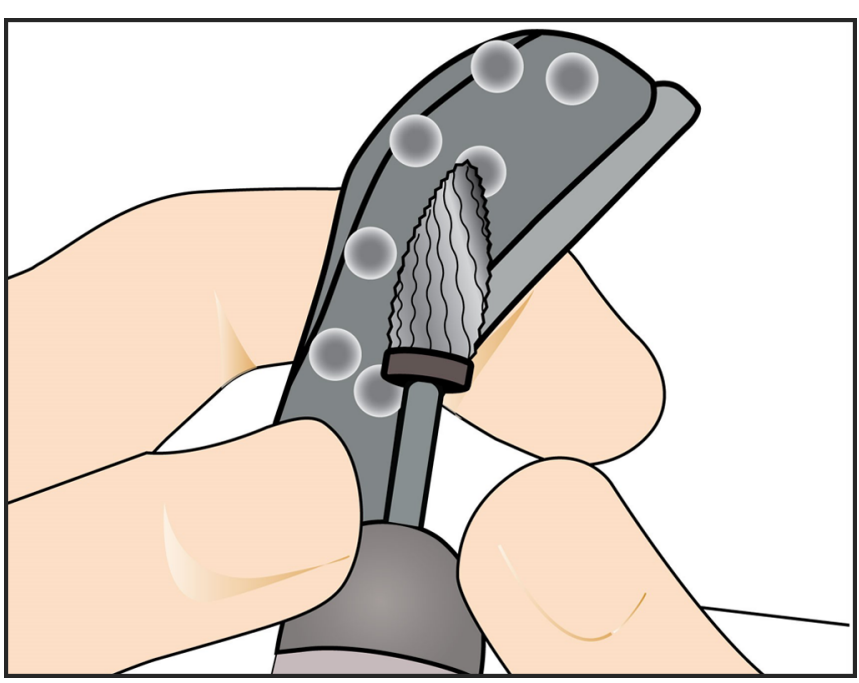

an arched step on the vestibular surface of the denture, with a depth of $1.0 \mathrm{~mm}$ and a height of $1.5 \mathrm{~mm}$ [Figure 2].

Fig. 2. Abrading of the prosthetic edge and formation of an arched step
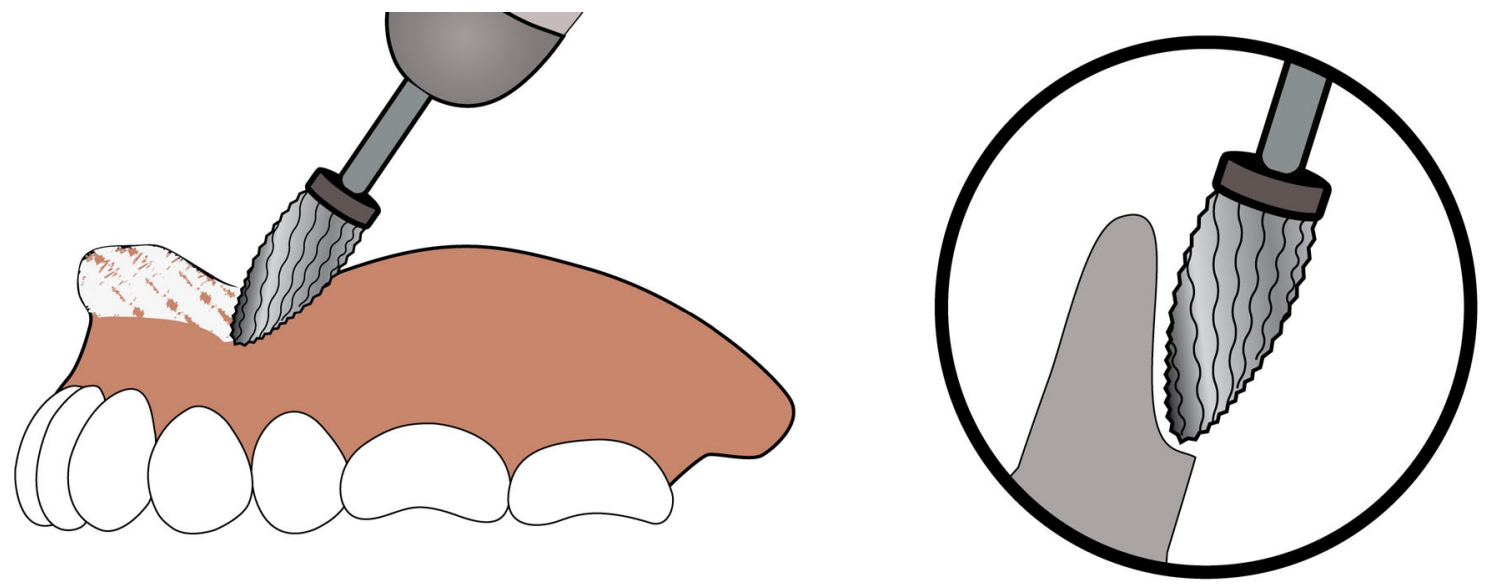
The described method of mechanical treatment does not apply to resilient materials, which have a weak bond with the hard acrylic resin. In such cases, the relining layer should reach the prosthetic edge [9].

The next clinical steps include application of an ad- hesive (primer) for the time defined by the manufacturer's instructions; application of the resilient material; inserting the denture into the patient's mouth and pressing against the prosthetic field [Figure 3]. Generally, polymerization is completed in about 5 minutes.

Fig. 3. Application of the resilient material
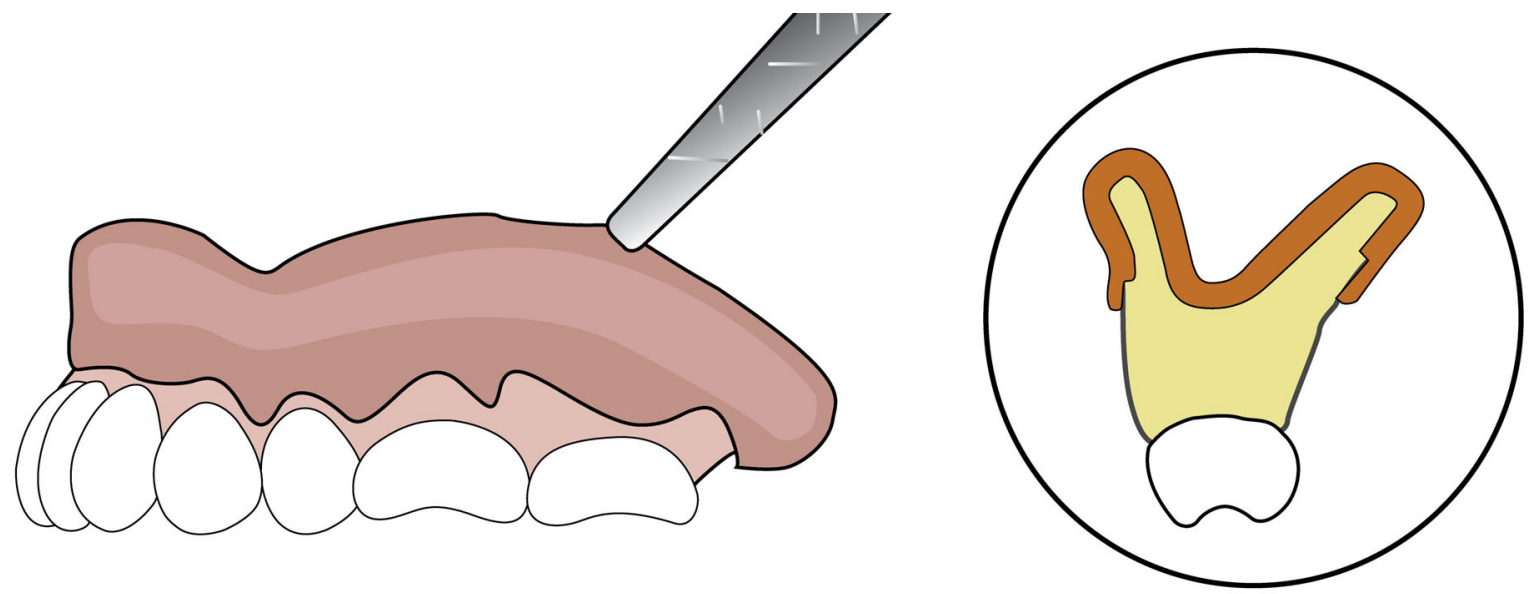

\section{Direct-indirect technique}

The first step of the direct-indirect technique is to make a functional impression with the pre-fabricated hard acrylic denture. The denture is used as a customized impression tray. It is recommended to obtain the functional impression with the mouth closed (by Popov) and by using soft tests [31]. The next technological steps are laboratory.

A gypsum working model is cast, which, together with the denture, is mounted on an articulator or a special cuvette-key, to preserve the intermaxillary relation [33] [Figure 4].

Fig. 4. Mounting on an articulator

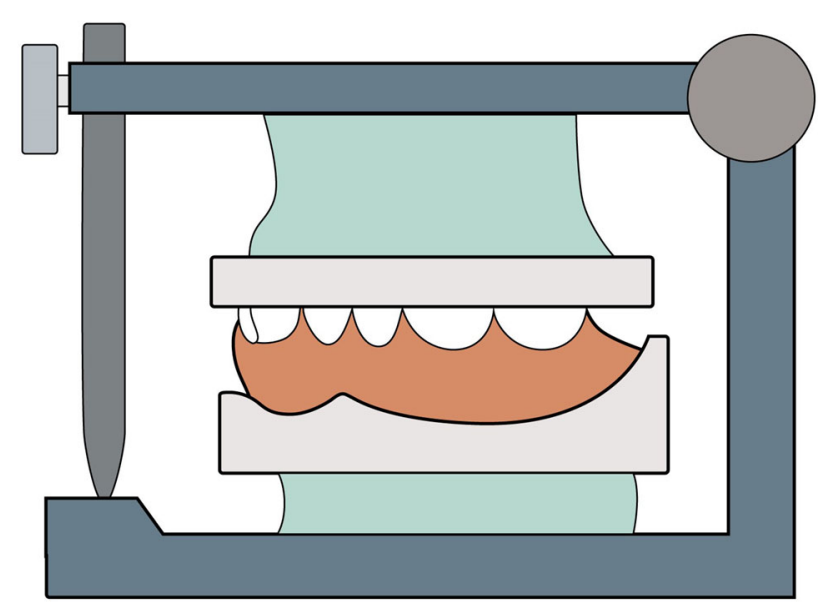

The impression material is removed and the prosthetic surface is treated by abrading as in the direct technique. When the provision of a uniform space for the resilient material is done by abrading, it should be borne in mind that the impression material also provides a certain space, so the abrasion has to be reduced.

Providing a uniform space for the resilient material can also be done by the method, described by Abe [32], by placing hard resin spacers before taking the impression. The application of resilient material is planned at the start of treatment, to prevent errors in determining the level of the masticatory plane and the intermaxillary relation. The next steps include application of a primer on the mucosal surface of the denture, application of the resilient material and remounting on an articulator (cuvette-key) [Figure 5].

Fig. 5. Denture with resilient material, mounted on an articulator

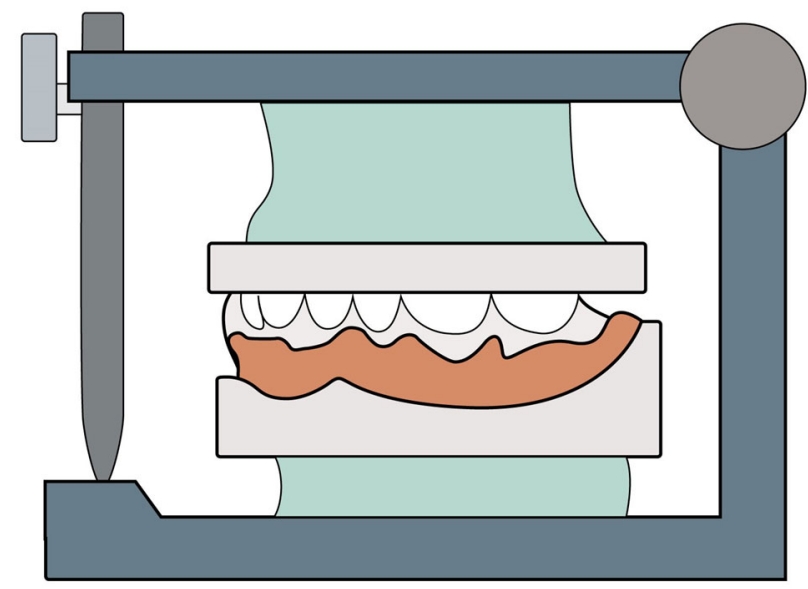

Depending on the material, polymerization takes place under the following parameters:

- at room temperature for about 20-30 minutes

- in a polymerization apparatus at $40^{\circ} \mathrm{C}-45^{\circ} \mathrm{C}$ and pressure of 1.7-2.4 atm. for about 5-15 minutes. Baysan et al. [34] describe microwave polymerization for 5 minutes 
at $650 \mathrm{~W}$.

According to other sources [8], already in 1992, a modified technique for extending the life of tissue conditioners included additional heat treatment.

\section{Indirect Technique}

All heat-curing resilient materials require indirect, all-laboratory technique. The hard acrylic denture has no contact with the patient before application of the resilient lining. The so-called double-layer dentures are fabricated, with pre-planned lining with resilient material.

Some silicone-based heat-curing resilient materials, such as Molloplast B (Detax, GmbH \& Co. KG, Germany), Luci-Sof (Dentsply Int., USA) and others, require heat treatment for 2.0-2.5 h. The bond with the hard acrylic resin is accomplished by means of a primer, when the prosthesis is polymerized in advance. A better bond is obtained, when the resilient material is applied against unpolymerized acrylic resin and the polymerization is performed simultaneously for both materials [35, 36, 37]. This technology is described in detail by MacEntee [38] and Hayakawa [9]. Using a spacer is a must.

The laboratory steps to the application of acrylic resin are not different from conventional technology. After evaporation of the wax, a spacer, which can be made of wax $[9,38]$, silicone [39], self-curing or light-curing resin [40] or vacuum-pressed thermofoil plate [41], is placed on the model. The use of a spacer provides a uniform thickness of the resilient material [42]. An acrylic resin is placed on the other half of the cuvette, followed by a test-closure and pressing, using a sheet of polyethylene foil. The cuvette is opened, the spacer is removed and the resilient material is placed in place. Again, a test closure and pressing is performed, the cuvette is opened and the excess resilient material is removed. The cuvette is closed, tightened in a mechanical or hydraulic press for 10-15 minutes and placed in a polymerization apparatus.

The polymerization of Molloplast B (Detax, $\mathrm{GmbH}$ \& Co, KG, Germany) takes places for about 2 hours at $100^{\circ} \mathrm{C}$. It can also be done in a microwave apparatus for 10 minutes at $850 \mathrm{~W}$. The application of Luci-Sof (Dentsply Int., USA) is done on pre-polymerized acrylic resin by using an adhesive. The polymerization takes place for 2.5 hours. The acrylic-based heat-curing resilient resin EverSoft (Dentsply Int., USA) is also applied to pre-polymerized hard acrylic resin. The bond between the two materials is chemical.

Indirect and direct-indirect techniques provide better bonding and longer functional life [43, 44]. Direct technique is used for temporary resilient liners or tissue conditioners [45].

\section{CONCLUSION}

Good knowledge of the types of resilient lining materials and lining techniques, as well as their characteristics is a prerequisite for the predictable final outcome of this type of prosthetic treatment.

\section{REFERENCES:}

1. Dimova-Gabrovska M, Dimitrova D. Application of Artificial Posterior Teeth with 0-Degree of Cuspal Angulations in Removable Prosthesis - Literature Review. Scientific works of the Union of Scientists in Bulgaria - Plovdiv. 2018; 12(1):224-230.

2. Dimova-Gabrovska $M$, Dimitrova D. Application of 20-Degrees Teeth in Removable Prosthetics - Literature Review. Scientific works of the Union of Scientists in Bulgaria - Plovdiv. 2018;12(1):230-236.

3. Dimova-Gabrovska MI, Mitronin VA, Dimitrova DG. [Features of the analysis of the maximum bite force in patients with complete dentures in the position of the central occlusion.] Actual issues of modern dentistry. To the 110-th anniversary of the birth of Professor V. Yu. Kurlandski. Moscow 2018; 93-95. [in Russian]
4. Todorov Iv. [Material Science.] Medicine and Physical Education. Second ed. 1989. pp.102-104. [in Bulgarian]

5. Anastasov I. [Science of Dental Materials.] Sofia Smile Center. Sofia. 2013: 159-161. [in Bulgarian]

6. Bansal S, Bansal S, Khosla A, Kaur S. Comparative evaluation of the effect of different denture cleansers on the tensile bond strength of permanent soft liner to polymethyl methacrylate. Indian J Dent Sci. 2014 Dec; 6(5):1-4.

7. Chladek G, Zmudzki J, Kasperski J. Long-Term Soft Denture Lining Materials. Materials Based. 2014 Aug;7(8): 5816-5842. [Pubmed] [Crossref]

8. Rodrigues S, Shenoy V, Shetty T. Resilient liners: A review. J Indian Prosthodont Soc. 2013 Sep;13(3): 155-64. [PubMed] [Crossref]

9. Hayakawa I. Principles and prac- tices of complete dentures: Creating the mental image of a denture. 1st edition. Quintessence Publishing, Germany. 1999. pp.233-248.

10. Hayakawa I, Keh ES, Morizawa M, Muraoka G, Hirano S. A new polyisoprene-based light-curing denture soft lining material. J Dent. 2003 May;31(4):269-74. [PubMed] [Crossref]

11. Canay S, Hersek N, Tulunoglu I, Uzun. G. Evaluation of colour and hardness changes of soft lining materials in food colorant solutions. $J$ Oral Rehabil. 1999 Oct;26(10):8219. [PubMed] [Crossref]

12. Kim B, Yang H, Chun M, Park YJ. Shore hardness and tensile bond strength of long-term soft denture lining materials. J Prosthet Dent. 2014 Nov;112(5):1289-97. [PubMed] [Crossref]

13. Maeda T, Hong G, Sadamori Sh, Hamada T, Akagawa Y. Durability 
of peel bond of resilient denture liners to acrylic denture base resin. $J$ Prosthodont Res. 2012 Apr;56(2): 136-41. [PubMed] [Crossref]

14. Mante F, Mante M, Petropolous V. In vitro changes in hardness of sealed resilient lining materials on immersion in various fluids. $J$ Prosthodont. 2008 Jul;17(5):384-91. [PubMed] [Crossref]

15. Polyzois G, Frangou M. Influence of curing method, sealer, and water storage on the hardness of a soft lining material over time. J Prosthodont. 2001 Mar;10(1):42-5. [PubMed]

16. Pathak C, Priyanka T, Pawah S, Gupta A. Soft liners in prosthodontics: A review. Indian J Dent Sci. 2014 Sep;6(5):093-095.

17. Parr G, Rueggeberg F. In vitro hardness, water sorption, and resin solubility of laboratory-processed and autopolymerized long-term resilient denture liners over one year of water storage. J Prosthet Dent. 2002 Aug; 88(2):139-144. [PubMed] [Crossref]

18. Qudah S, Harisson A, Huggett R. Soft lining materials in prosthetic dentistry: a review. Int J Prosthodont 1990 Sep-Oct;3(5):477-483. [PubMed]

19. Mainieri V, Beck J, Oshima H, Hirakata L, Shinkai R. Surface changes in denture soft liners with and without sealer coating following abrasion with mechanical brushing. Gerodontology. 2011 Jun;28(2):146-51. [PubMed]

20. Taira Y, Sekine J, Sawase T, Atsuta M. Implant-retained overdenture following hemiglossectomy: a 10year clinical case report. J Oral Rehabil. 2006 Apr;33(4):313-315. [Crossref]

21. Murata H, Kawamura M, Hamada T, Saleh S, Kresnoadi U, Toki K. Dimensional stability and weight changes of tissue conditioners. J Oral Rehabil. 2001 Oct;28(10):918-923. [PubMed] [Crossref]

22. Altarawneh $\mathrm{S}$, Bencharit $\mathrm{S}$, Mendoza L, Curran A, Barrow D, Barros S, et al. Clinical and histological findings of denture stomatitis as related to intraoral colonization patterns of Candida albicans, salivary flow, and dry mouth. J Prosthodont. 2013 Jan;22(1):13-22. [PubMed] [Crossref]

23. Mutluay M, Ruyter I. Evaluation of bond strength of soft relining materials to denture base polymers. Dental Materials. 2007 Nov;23(11): 1373-1381. [PubMed] [Crossref]

24. Dimova M, Hadzhieva X, Peev T. [Protocol for registration of the data from the review of the completely edentulous patients]. Dental Medicine. 2009;1(1):34-40. [in Bulgarian]

25. Jagger D, Harrison A. Complete dentures - the soft option. An update for general dental practice. $\mathrm{Br}$ Dent J. 1997 Apr;182(8):313-317. [Crossref]

26. Mese A, Guzel K. Effect of storage duration on the hardness and tensile bond strength of silicone- and acrylic resin-based resilient denture liners to a processed denture base acrylic resin. J Prosthet Dent. 2008 Feb;99(2):153-158. [PubMed] [Crossref]

27. Abe Y. Study of Clinical Science and Engineering Silicone Denture Reline Material Mucopren ${ }^{\circledR}$ soft. The Nippon Dental Review. 2008; 68(8):113-118. [Internet]

28. Kial-Amnuay S, Gettleman L, Mekayarajjananonth T, Khan Z, Goldsmith L. The Influence of Water Storage on Durometer Hardness of 5 Soft Denture Liners over Time. J Prosthodont. 2005 Mar;14(1):19-24. [PubMed], [Crossref]

29. Zissis A, Polyzois G, Jagger R, Waters M. Wettability of Visible Light-Curing denture lining materials. Int J Prosthodont. 2001 MayJun;14(3):250-254. [PubMed]

30. Zissis A, Polyzois G, Yannikakis S, Harrison A. Roughness of Denture Materials: A Comparative Study. Int J Prosthodont. 2000 MarApr;13(2):136-140. [PubMed]

31. Popov N. [Clinic of Prosthetic Dentistry.] Medicine and Physical Education. Sofia 1992. 246-248. [in Bulgarien]

32. Tata, S, Nandeeshwar D. A
Clinical Study to Evaluate and Compare the Masticatory Performance in Complete Denture Wearers with and without Soft Liners. J Contemp Dent Pract. 2012 Nov;13(6):787-792. [PubMed]

33. Peev T, Filchev A. [Clinic of Prosthetic Dental Medicine.] Sofia 2008. 230-232. [in Bulgarian]

34. Baysan A, Parker S, Wright P. Adhesion and tear energy of a long term soft lining material activated by rapid microwave energy. J Prosthet Dent. 1998 Feb;79(2):182-187. [PubMed] [Crossref]

35. Demir H, Dogan A, Dogan OM, Keskin S, Bolayir G, Soygun K. Peel bond strength of two silicone soft liners to a heat-cured denture base resin. J Adhes Dent. 2011 Dec; 13(6):579-84. [PubMed] [Crossref]

36. Kawano F, Dootz E, Koran A, Craig R. Bond strength of six soft denture liners processed against polymerized and unpolymerized poly(methyl methacrylate). Int $J$ Prosthodont. 1997 Mar-Apr;10(2): 178-182. [Pubmed]

37. Muralidhar G, Satish Babu C, Shetty S. Integrity of the interface between denture base and soft liner: A scanning electron microscopic study. J Indian Prosthodont Soc. 2012 Jun; 12(2):72-77. [Crossref]

38. MacEntee Michael I. The Complete Denture, A Clinical Pathway. Quintessence Publishing Co Inc. 1999. 89-95.

39. Kutay O. A silicone rubber spacer used to determine the optimum thickness for hard and resilient materials in complete dentures. $J$ Prosthet Dent. 1993;69(3):329-32. [PubMed] [Crossref]

40. Huband M. Spacer made from a visible light-cured resin for processing denture soft liners. J Prosthet Dent. 1992 Sep;68(3):542-544. [Crossref]

41. Reeson MG, Jepson NJ. A simple method for obtaining a uniform thickness for long-term soft denture linings. J Prosthet Dent. 1998 Mar;79(3):355-7. [Pubmed] [Crossref] 
42. Agrawal H, Shah R, Jhala N. A Comparison between Two Ways of Relining with Soft Denture Lining Materials (an in-vitro study). Sch J App Med Sci. 2014; 2(1A):61-66.

43. Dimova M, Hadjieva H, Peev T. Individual transferring of clinical and paraclinical data by total rehabilitation of patients with compromised stability of the full dentures. A pilot study. J of IMAB. 2005 Apr;11(2):45-

\section{7. [Internet]}

44. Dimova M, Hadzhieva H, Peev

T. [Documented transfer of data and instructions between the clinic and the laboratory for total prosthesis.] Dental examination. 2006; 2(1):103107. [in Bulgarian]

45. Grant A, Heath J, McCord J. Complete prosthodontics - problems, diagnosis and management. Wolfe. 1994. 123-125.

Please cite this article as: Yankova M, Yordanov B, Dimova-Gabrovska M, Apostolov N. Resilient Lining Materials for Removable Dentures: Types, Composition and Technology. J of IMAB. 2019 Jul-Sep;25(3):2632-2639.

DOI: https://doi.org/10.5272/jimab.2019253.2632

Received: 02/04/2019; Published online: 25/07/2019

Address for correspondence

Dr. Mariana Yankova, PhD

Department of Prosthetic Dental Medicine, Faculty of Dental Medicine, Medical University, Sofia,

1, St. G. Sofiiski blvd., Sofia, Bulgaria

E-mail: marianayankova13@gmail.com,m.jankova@abv.bg; 